\title{
ERS statement on tracheomalacia and bronchomalacia in children
}

\author{
Colin Wallis ${ }^{1}$, Efthymia Alexopoulou ${ }^{2}$, Juan L. Antón-Pacheco ${ }^{3}$, Jayesh M. Bhatt $\mathbb{C}^{4}$, \\ Andrew Bush ${ }^{5}$, Anne B. Chang ${ }^{6,7,8}$, Anne-Marie Charatsi ${ }^{9}$, Courtney Coleman ${ }^{10}$, \\ Julie Depiazzi ${ }^{11}$, Konstantinos Douros ${ }^{12}$, Ernst Eber ${ }^{13}$, Mark Everard ${ }^{14}$, \\ Ahmed Kantar ${ }^{15}$, lan B. Masters ${ }^{6,7}$, Fabio Midulla ${ }^{16}$, Raffaella Nenna (16,17, \\ Derek Roebuck $^{18}$, Deborah Snijders ${ }^{19}$ and Kostas Priftis ${ }^{12}$
}

@ERSpublications

This statement provides a comprehensive review of the causes, presentation, recognition and management of children with tracheobronchomalacia written by a multidisciplinary Task Force in keeping with ERS methodology http://bit.ly/2LPTQCk

Cite this article as: Wallis C, Alexopoulou E, Antón-Pacheco JL, et al. ERS statement on tracheomalacia and bronchomalacia in children. Eur Respir J 2019; 54: 1900382 [https://doi.org/10.1183/13993003.003822019].

ABSTRACT Tracheomalacia and tracheobronchomalacia may be primary abnormalities of the large airways or associated with a wide variety of congenital and acquired conditions. The evidence on diagnosis, classification and management is scant. There is no universally accepted classification of severity. Clinical presentation includes early-onset stridor or fixed wheeze, recurrent infections, brassy cough and even near-death attacks, depending on the site and severity of the lesion. Diagnosis is usually made by flexible bronchoscopy in a free-breathing child but may also be shown by other dynamic imaging techniques such as low-contrast volume bronchography, computed tomography or magnetic resonance imaging. Lung function testing can provide supportive evidence but is not diagnostic. Management may be medical or surgical, depending on the nature and severity of the lesions, but the evidence base for any therapy is limited. While medical options that include bronchodilators, anti-muscarinic agents, mucolytics and antibiotics (as well as treatment of comorbidities and associated conditions) are used, there is currently little evidence for benefit. Chest physiotherapy is commonly prescribed, but the evidence base is poor. When symptoms are severe, surgical options include aortopexy or posterior tracheopexy, tracheal resection of short affected segments, internal stents and external airway splinting. If respiratory support is needed, continuous positive airway pressure is the most commonly used modality either via a face mask or tracheostomy. Parents of children with tracheobronchomalacia report diagnostic delays and anxieties about how to manage their child's condition, and want more information. There is a need for more research to establish an evidence base for malacia. This European Respiratory Society statement provides a review of the current literature to inform future study.

This document was endorsed by the ERS Executive Committee on 18 June 2019.

This article has supplementary material available from erj.ersjournals.com

Received: 23 Feb 2019 | Accepted after revision: 16 May 2019

Copyright OERS 2019 


\section{Introduction}

Tracheomalacia (TM) is a condition of excessive tracheal collapsibility, due either to disproportionate laxity of the posterior wall (pars membranacea) or compromised cartilage integrity. As a result, the anterior and posterior walls appose, reducing the tracheal lumen opening and creating a shape abnormality during bronchoscopy $[1,2]$. TM may be localised or generalised $[2,3]$. If the main bronchi are also affected the condition is called tracheobronchomalacia (TBM). The term bronchomalacia (BM) is used when the excessive collapsibility is restricted to one or both of the mainstem bronchi and/or their divisions at the lobar or segmental level $[3,4]$. Cases of isolated BM as well as extrathoracic or cervical TM are relatively rare $[5,6]$.

Malacia is defined in this European Respiratory Society (ERS) Task Force report as an arbitrary $>50 \%$ expiratory reduction in the cross-sectional luminal area during quiet respiration [7-13]. There is no universally agreed "gold standard" diagnostic test, although flexible bronchoscopy is the most commonly used modality by respiratory paediatricians. The degree of TM/TBM can be assessed either bronchoscopically or radiologically. There is also no universally accepted classification of severity. In clinical practice, the anatomical changes are arbitrarily described as mild (50-75\% reduction), moderate (75-90\% reduction) or severe ( $>90 \%$ reduction), most often on the subjective visual inspection at bronchoscopy [14]. This is a purely descriptive system of classification that does not reflect clinical severity since the degree of lumen occlusion is not associated with disease morbidity (see the later section on clinical signs and symptoms).

The expiratory recoil pressure of the chest wall leads to a dynamic increase in intrathoracic pressure, which is transmitted to the airways. If the large intrathoracic airways are normal, changes in calibre are negligible but occur, for example, with coughing. If there is malacia, the tracheal/bronchial walls collapse with partial or complete occlusion of the lumen $[15,16]$, in particular if expiratory efforts are increased due to airflow obstruction. The adult literature distinguishes between collapse of the pars membranacea and the cartilaginous wall. Some use the term hyperdynamic airway collapse to describe the excessive protrusion of the posterior trachealis muscle into the central airway lumen during expiration, and reserve the terms TM and TBM for the collapsibility of central airways due to the loss of structural integrity of the affected cartilaginous rings [17-19]. Because of the intrinsic softness of the paediatric tracheal cartilages, this distinction is less clear in the newborn, infant and young child. For the purposes of this report, TM and TBM will also encompass hyperdynamic airway collapse.

This ERS Task Force report on paediatric TBM reviews the current literature in children, describing the evidence for diagnosis, clinical impact and therapeutic options, and the impact on families and patients, with suggestions for future research.

\section{Methodology}

The ERS Task Force on TM and BM in children comprised a group of paediatric respiratory physicians, a paediatric chest surgeon, paediatric radiologists, a physiotherapist, an early career member of the ERS, a European Lung Foundation representative and an ERS methodologist providing expertise in statement development. ERS standardised procedures for conflict of interest declaration were followed.

Affiliations: ${ }^{1}$ Respiratory Medicine Unit, Great Ormond Street Hospital for Children, London, UK. ${ }^{2}$ 2nd Radiology Dept, National and Kapodistrian University of Athens, Attikon University Hospital, Athens, Greece. ${ }^{3}$ Pediatric Airway Unit and Pediatric Surgery Division, Universidad Complutense de Madrid, Madrid, Spain. ${ }^{4}$ Nottingham University Hospitals NHS Trust, Queen's Medical Centre, Nottingham, UK. 5 Imperial College London and Royal Brompton and Harefield NHS Foundation Trust, London, UK. ${ }^{6}$ Dept of Respiratory and Sleep Medicine, Queensland Children's Hospital, Brisbane, Australia. ${ }^{7}$ Centre for Children's Health Research, Institute of Health and Biomedical Innovation, Queensland University of Technology, Brisbane, Australia. ${ }^{8}$ Child Health Division, Menzies School of Health Research, Charles Darwin University, Casuarina, Australia.

${ }^{9}$ Pediatric Dept, Centre Hospitalier de Luxembourg, Luxembourg, Luxembourg. ${ }^{10}$ European Lung Foundation, Sheffield, UK. ${ }^{11}$ Physiotherapy Dept, Perth Children's Hospital, Perth, Australia. ${ }^{12}$ Allergology and Pulmonology Unit, 3rd Paediatric Dept, National and Kapodistrian University of Athens, Athens, Greece.

${ }^{13}$ Division of Paediatric Pulmonology and Allergology, Dept of Paediatrics and Adolescent Medicine, Medical University of Graz, Graz, Austria. ${ }^{14}$ Division of Paediatrics, University of Western Australia, Perth Children's Hospital, Perth, Australia. ${ }^{15}$ Pediatric Asthma and Cough Centre, Istituti Ospedalieri Bergamaschi, University and Research Hospitals, Bergamo, Italy. ${ }^{16}$ Dept of Paediatrics, "Sapienza" University of Rome, Rome, Italy.

${ }^{17}$ Asthma and Airway Disease Research Center, University of Arizona, Tucson, AZ, USA. ${ }^{18}$ Interventional Radiology Dept, Great Ormond Street Hospital, London, UK. ${ }^{19}$ Dipartimento Salute della Donna e del Bambino, Università degli Studi di Padova, Padova, Italy.

Correspondence: Colin Wallis, Respiratory Medicine Unit, Great Ormond Street Hospital for Children, Great Ormond Street, London, WC1N 3JH, UK. E-mail: colin.wallisdgosh.nhs.uk 
The Task Force started with a teleconference in May 2017 to agree on the formulation of questions and allocate work into 12 pairs. Each pair was allocated a key question and undertook their own literature search using relevant key words in systematic reviews, randomised controlled trials, case series, and reviews and observational studies, over the last 20 years (1997-2017), from Scopus and MEDLINE (accessed via PubMed) databases, restricted to the English language. Details of the original questions, the allocated Task Force members, results of the searches and PRISMA diagrams are provided in the supplementary material. There were face-to-face meetings during the ERS International Congress in Milan (Italy) in September 2017 and another 2-day meeting in Athens (Greece) in March 2018. Literature published subsequent to the final meetings was not included in this review.

Drafts were submitted to the Task Force chairs and integrated into a uniform manuscript, which was extensively discussed at the third face-to-face meeting during the ERS International Congress in Paris (France) in September 2018. All Task Force members further reviewed and contributed to the manuscript in its final form.

\section{Conditions associated with TBM}

There is no generally accepted paediatric classification of the causes of airway malacia. The Task Force used a division into those conditions with an intrinsic alteration of airway cartilage (primary or congenital) and those where the cartilage was embryologically normal but developmentally malformed because of pressure on the airway wall from outside (secondary) or acquired from airway luminal disease such as chronic infection.

Pragmatically, it may also be helpful to distinguish conditions where TBM is clinically the main problem and those in which, while still a factor, there are either more important complex extrapulmonary comorbidities such as cardiovascular abnormalities or pulmonary parenchymal disease. An example of the latter would be bronchopulmonary dysplasia, in which TBM worsens the prognosis but is far from the only abnormality [20].

The numerous causes of TBM are summarised in table 1. Congenital airway malacia is part of many rare syndromes. TM can be found in association with chromosomal defect syndromes, mucopolysaccharidoses and inherited connective tissue disorders [21]. In addition, TM has been described in $\sim 5 \%$ of children with achondroplasia [22]. Some conditions are associated with a discrete area of malacia. For example, children with tracheo-oesophageal fistula (TOF) typically have a short segment of TM post-operatively [18, $23,24]$; post-operative repair of vascular rings can leave a defined, short tracheomalacic defect.

One study reported malacia (including laryngomalacia, a condition beyond the remit of this Task Force report) in 299 out of 885 bronchoscopies [3]. 41 had cardiovascular abnormalities, 29 had been treated for TOF, nine had congenital lobar emphysema and 24 were syndromic. BOOGAARD et al. [25] found BM in 160 out of 512 paediatric flexible bronchoscopies, 136 cases being primary. 67 out of 86 children with primary malacia in whom bronchoalveolar lavage was obtained had a positive bacterial culture; lavage neutrophil counts were not reported. Whether infection was secondary to malacia, or the converse, and the relationship between malacia and persistent bacterial bronchitis is also unclear.

It has been suggested that infant wheeze may be related to TBM [26] as a developmental phenomenon with spontaneous recovery, but the contribution of malacia is rarely determined in clinical practice.

\section{Clinical symptoms and signs}

The type and onset of symptoms depend on length, site and severity of the malacic segment. The Task Force members were unable to find any consistent correlation between anatomical severity and clinical features in the literature.

Symptoms may be persistent or intermittent and of varying severity $[6,27]$. If the extrathoracic trachea is malacic there may be stridor; if intrathoracic, a monophonic expiratory wheeze is common $[6,28]$. If the child develops a respiratory infection, there may be a barking cough, prolonged resolution of cough, expiratory wheeze or croup-like symptoms. Older patients often complain that complete exhalation is difficult [18].

In more symptomatic cases, stridor or wheezing are persistent, respiratory infections are frequent and respiratory distress may occur. Wheezing in children with malacia is typically centrally located, low pitched and monophonic [29], and distinct from the diffuse, high-pitched and musical wheezing in asthma. Moreover, in patients with malacia, wheezing remains unchanged or even worsens after bronchodilator inhalation [15]. Importantly, TM/BM should always be considered in the differential diagnosis of infants and pre-school children with "atypical wheeze" (e.g. infants who are never completely symptom-free or infants with frequently recurring wheeze). The "bagpipe sign", an expiratory sibilant 
TABLE 1 Summary of causes of tracheomalacia (TM), bronchomalacia (BM) and tracheobronchomalacia (TBM)

\section{Primary or congenital}

Congenital idiopathic

Idiopathic TM/BM (may be genetic factors)

\section{Congenital abnormalities of the cartilage}

Dyschondroplasia/chondromalacia/ achondroplasia

Left bronchial isomerism with normal atrial arrangement

Congenital anomalies of the aerodigestive tract

Oesophageal atresia (with or without laryngeal cleft)

Anomalies of respiratory tract development

Prematurity

Congenital syndromes associated with TM/TBM

Mucopolysaccharidosis (Hurler syndrome, Hunter syndromel

Trisomy 9

Smith's syndrome

Cotello's syndrome

Arthrogryposis

Antley-Bixler syndrome; $11 \mathrm{p} 13$ deletion;

$16 p 13.3$ deletion; 22q11 deletion

Pfeiffer syndrome

Kniest dysplasia

Deletion of $12 q$

Brachmann-de Lange syndrome

Pierre Robin syndrome

Chitayat syndrome

Late-onset Pompe's disease

Osteogenesis imperfect

\section{Secondary or acquired}

Cardiovascular anomalies associated with TM/BM

Double aortic arch

Right aortic arch

Left atrial hypertrophy

Left to right shunting leading to enlarged pulmonary arteries

Skeletal anomalies associated with TM/BM Scoliosis

Infections and inflammatory processes associated with TM/TBM

Severe tracheobronchitis

Chronic suppurative lung disease, including

cystic fibrosis, primary ciliary dyskinesia,

other causes of bronchiectasis

Tracheobronchial injury associated with TM/TBM

Button battery ingestion injury

Medical procedures and surgery associated with TM/TBM

Prolonged intubation

Laryngotracheal reconstruction

Fetal balloon insertion for congenital diaphragmatic hernia

Tumours and cysts associated with TM/TBM

Primary tracheal tumour

Goitre

Neuroblastoma

Enterogenous cysts

Ehlers-Danlos syndromes

Marfan syndrome

TOF

Bronchopulmonary dysplasia

CHARGE syndrome

Trisomy 21

Opitz syndrome

Neurofibromatosis

Atelosteogenesis type 1

Partial trisomy of long arms of chromosomes 11 and 22

Blackfan-Diamond anaemia Diastrophic dysplasia

Cariofaciocutaneous syndrome

Camptomelic dysplasia

Crouzon syndrome

Spondyloepiphyseal dysplasia congenital

Loeys-Dietz syndrome

Hallermann-Streiff syndrome

Dilated cardiomyopathy

Aberrant right subclavian

Enlarged left atrium

Tetralogy of Fallot with absent

pulmonary valve syndrome

Pectus excavatum

Protracted bacterial bronchitis Relapsing polychondritis

Delayed removal of inhaled foreign body

Tracheostomy

Tracheoplasty

Teratomas

Lymphatic malformation

Haemangiomas

Cystic hygromas
VATER anomaly

Cri du chat syndrome Goldenhaar syndrome Allagille's syndrome 18-22 translocation Larsen syndrome and Larsenlike syndromes

Williams-Campbell syndrome

DiGeorge syndrome Fryn's syndrome

De la Chapelle dysplasia Noonans syndrome Spondylocostal dysostosis Filamin A mutation

Pulmonary arterial sling Enlarged pulmonary veins Severe PAH

Abnormal take-off of the innominate artery

Stevens-Johnson syndrome

CHARGE: coloboma, heart anomaly, choanal atresia, retardation, genital and ear anomalies; VATER: vertebrae, anus, trachea, oesophagus and renal; PAH: pulmonary arterial hypertension; TOF: tracheo-oesophageal fistula.

sound that persists after the end of visible expiration, may also be present [6]. Intermittent compression of a malacic trachea during bolus progression in the oesophagus can cause desaturation, leading to poor feeding and, consequently, poor weight gain. 
In severe cases, airway obstruction with cyanosis, inspiratory and expiratory stridor during tidal breathing, apnoea, and even cardiac arrest or sudden infant death may occur [6, 27, 30-32]. In the most severe cases, airway obstruction can only be resolved with intubation [6, 27] and successful extubation can be challenging [33]. Tracheal obstruction can cause "dying spells" (also called "apnoeic spells", "reflex apnoea", "death attacks" or "blue spells"). These events are possibly elicited by a reflex triggered by secretions or when a bolus of food in the oesophagus compresses the trachea or the presence of increased intrathoracic pressure from a Valsalva effect.

Severe malacia is typically evident clinically from birth, but many children with TM or BM do not show any symptoms before age 2-3 months [6, 27, 30]. BOogAARD et al. [25] described symptoms in 96 outpatients with primary airway malacia and without comorbidities. Cough was found in $83 \%$ of children (night-time cough 42\%; productive cough 60\%; exercise-induced cough $35 \%$; characteristic barking cough $43 \%$ ), recurrent lower airway infections in $63 \%$, dyspnoea in $59 \%$, recurrent wheeze in $49 \%$, recurrent rattling in $48 \%$, reduced exercise tolerance in $35 \%$, symptoms of gastro-oesophageal reflux (GOR) in $26 \%$, retractions in 19\%, stridor in $18 \%$ and funnel chest in $10 \%$ [25]. However, in many patients symptom onset is insidious and for some the diagnosis is only made later in life [25], even in the elderly [34].

Table 2 summarises symptoms and signs of TM/BM. A barking or brassy cough is most commonly reported. Intra- and interobserver clinician agreement for brassy cough was very good $(\kappa=0.79,95 \% \mathrm{CI}$ 0.73-0.86) when undertaken by respiratory specialists, and the sensitivity and specificity of brassy cough (compared with TM seen at flexible bronchoscopy) were 0.57 and 0.81 , respectively [35]. The brassy cough is caused by vibration due to the mechanical juxtaposition of the anterior and posterior walls of the trachea [27], which causes an irritable focus that stimulates further cough [36]. In a meta-analysis including five studies with 455 patients in whom bronchoscopy was performed because of recurrent croup-like symptoms, TM was found in $4.6 \%$ of children [37].

In children with $\mathrm{TM} / \mathrm{BM}$, both airway closure during cough and ineffective cough due to an underlying condition can cause impaired clearance of secretion, leading to recurrent and/or prolonged respiratory infections [6, 27]. Santiago-Burruchaga et al. [38] demonstrated airway malacia in 52\% of 62 children in whom bronchoscopy was performed because of recurrent lower respiratory tract infections. Airway malacia is a frequent bronchoscopic finding in children with recurrent respiratory symptoms $[3,39,40]$ and in children with protracted bacterial bronchitis [41], although which is causal and which is secondary is often unclear.

In children with $\mathrm{TM} / \mathrm{BM}$, symptoms can be aggravated by any conditions requiring increased respiratory efforts, such as exercise, coughing, crying, feeding, Valsalva manoeuvres, forced expiration or lying supine. All these activities cause increased intrathoracic pressure that worsens airway collapse [6, 18]. Placing an infant in the prone position may open the airway because gravity pulls the mediastinal structures anteriorly, thus alleviating symptoms $[15,42]$.

\section{Natural history}

Symptoms may resolve in patients with primary nonsyndromic TM/BM. A greater tracheal diameter and increasing rigidity of the supporting cartilages with a more pronounced " $\mathrm{C}$ " shape of the cartilage rings with less protrusion of the pars membranacea (trachealis) often results in resolution of symptoms by age 1-2 years [27, 43, 44]. For some of these children, exercise intolerance or wheezing with exercise may persist into later childhood $[21,44]$.

\section{The role of pulmonary function testing in diagnosing TBM}

11 studies address the role of pulmonary function tests (PFTs) in diagnosing TM/TBM, but all are small and only two $[25,45]$ reported $\geqslant 20$ children. Many different PFTs were undertaken: spirometry, maximal flow at functional residual capacity ( $V^{\prime}$ maxFRC), FRC, peak expiratory flow, mid expiratory flow, tidal

TABLE 2 Common symptoms and signs of tracheomalacia/bronchomalacia in children

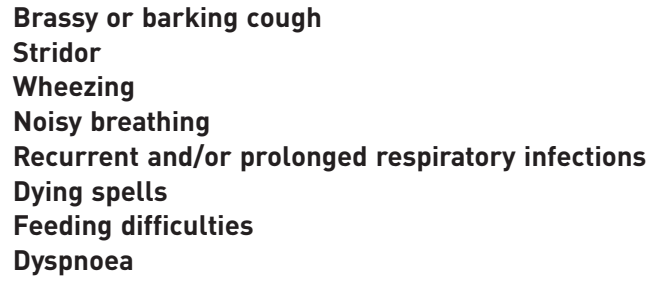


expiratory flow, airway resistance, flow-volume loop description and airway hyperresponsiveness. None of the studies used newer techniques such as oscillometry and multiple breath washout.

Many but not all studies showed that some children had expiratory airway obstruction. PFTs cannot be used to diagnose TBM, but an obstructive airway pattern is supportive evidence [46, 47]. Early-phase plateauing of the expiratory limb has been described. A plateau of both inspiratory and expiratory limbs of the flow-volume loop is more likely due to fixed obstruction, unless there is both intra- and extrathoracic TM [48]. Increased thoracic gas volume was also documented in one study [49]. Flow limitation during $V^{\prime}$ maxFRC is neither sensitive nor specific for malacia, but flow limitation during tidal breathing is highly predictive and $100 \%$ specific [50].

One study [46] found airway hyperreactivity to mannitol in two out of 15 (7\%) children, the significance of which is unclear. There was no significant effect of $\beta_{2}$-agonists on spirometry [25]. Indeed, $\beta_{2}$-agonists actually reduced $V^{\prime} \operatorname{maxFRC}$ by $31.6 \%$ in three children [51].

The studies are for the most part small and none related PFTs to severity of TBM or even defined how the diagnosis was made. Hence, we could not calculate the sensitivity and specificity of any PFT abnormality for TBM. PFTs may or may not be abnormal in children with TBM. Limited data exist on whether or not currently available PFTs can be used to diagnose TBM. Until further data are available, we are unable to quantify a precision of an estimate.

\section{The role of imaging to diagnose TBM}

The Task Force members could find no evidence to support the use of plain radiographs to diagnose TBM [52].

\section{Fluoroscopy}

Fluoroscopy is a quick, noninvasive dynamic study, with minimal radiation exposure $(\sim 0.01 \mathrm{mSv})$ and no requirement for sedation. Airway fluoroscopy is performed in the lateral position while the patient is free breathing $[27,53,54]$. The sensitivity is poor $(20-24 \%)$, while the specificity is very high $(93-100 \%)[55$, 56]. Fluoroscopy is often combined with a barium swallow to rule out the presence of an external compression.

\section{Multidetector computed tomography}

Multidetector computed tomography (MDCT) provides new diagnostic options (figure 1). Paired end-inspiratory and end-expiratory MDCT or paired end-inspiratory and dynamic expiratory MDCT are both reliable techniques $[7-9,57]$. Children age $<5$ years generally require intubation and controlled ventilation technique $[10,58]$, which will influence airway dynamics. In some institutions a securely positioned face mask is used instead of intubation, especially when a tracheal stenosis is suspected above the thoracic inlet level.

Intravenous contrast injection is only mandatory when looking for underlying compressive causes such as vascular abnormalities or mediastinal masses [10]. The reported overall diagnostic accuracy of paired airway MDCT compared with laryngoscopy/bronchoscopy is 91\% [9]. However, patients included in that study suffered from very severe TBM in whom surgery was required, so this was a biased population and the accuracy of the MDCT scan may have been overestimated [9]. Free-breathing cine-MDCT is an alternative technique in young children as it does not require general anaesthesia and controlled ventilation, and radiation exposure is low (mean effective dose $<2 \mathrm{mSv}$, with the minimum ever reported 0.19-0.8 mSv) [11-13]. Reported sensitivity (96.3\%) and specificity (97.2\%) are high compared with bronchoscopic evaluation [11]. Virtual bronchoscopy is not very sensitive (sensitivity <75\%) in detecting TM [59]. Only one study compared virtual bronchoscopy with flexible bronchoscopy, reporting a sensitivity of $54.1 \%$ and specificity of $87.5 \%$ for TM and $45.2 \%$ and $95.5 \%$ for BM [60].

MDCT has the advantage that it is a quick, less invasive technique that allows simultaneous assessment of any mediastinal, vascular and lung pathologies, as well as visualisation of airways distal to the obstruction [61]. The major disadvantage is the radiation exposure, which increases with the paired technique. This can be partially overcome by using reduced-dose techniques in the expiratory scan [62]. Another concern is the need for sedation and intubation in younger children, which can distort the airway and change the tracheal dynamics $[7,9,11,12,28]$. This problem can be partially solved by using free-breathing cine-MDCT [11-13].

\section{Dynamic MRI}

There are very limited publications, with small numbers of children, describing dynamic MRI to diagnose TBM. The major advantage of dynamic MRI is the lack of radiation exposure. Additionally, MRI provides 

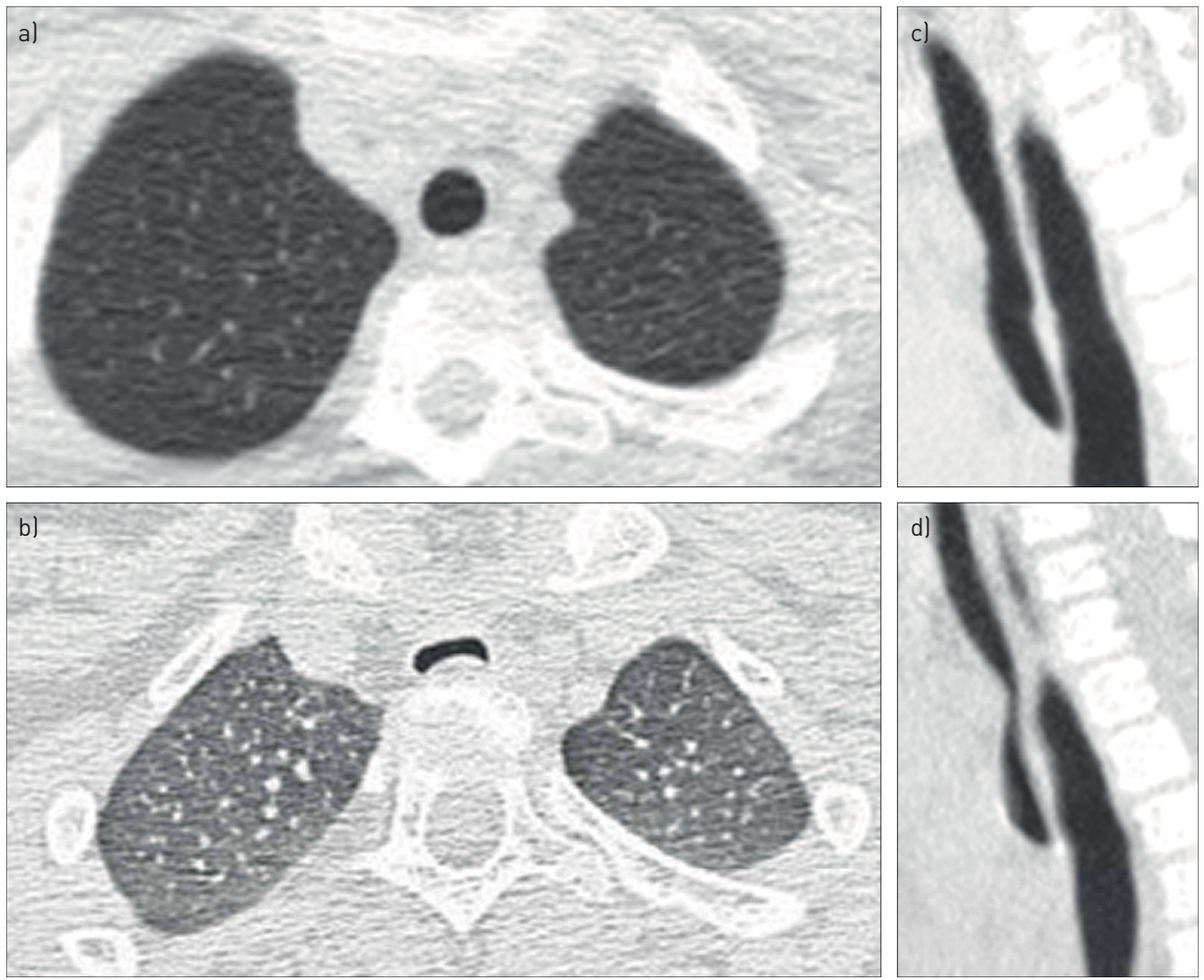

FIGURE 1 Paired end-inspiratory and end-expiratory multidetector computed tomography scans of the chest: axial scan at a) end-inspiration and b) end-expiration phase and sagittal multiplanar reconstruction at c) end-inspiration and d) end-expiration phase showing significant expiratory reduction in the cross-sectional luminal area of the trachea. The appearance is consistent with tracheomalacia.

high-resolution imaging with excellent soft tissue imaging, which allows for identification of vascular and mediastinal structures without necessarily the need for contrast [63], but the technique is time consuming.

Recent ultrafast sequences permit cine-MRI, which provides extremely rapid acquisition of images [63-65]. Another important advantage of cine-MRI, compared with bronchoscopy, is that in older children (usually $>8$ years) airways can be examined during static and dynamic breathing manoeuvres, such as forced expiration and cough, without any need for sedation or general anaesthesia, which could obscure TBM [65]. For younger children, sedation and/or general anaesthesia is necessary [64, 66]. A disadvantage of cine-MRI is the relatively low spatial resolution, which may be a problem with smaller calibre airways [63-65].

A published protocol describes the combination of static and dynamic cine-MRI [64, 65].

\section{Tracheobronchography}

Tracheobronchography performed with low volumes of nonionic water-soluble contrast is safe [67], and useful in the evaluation of TBM because of its high spatial and temporal resolution (figure 2) [68]. Many centres continue to use tracheobronchography [12,67, 69-71], often in combination with flexible bronchoscopy [68]. Free breathing, as with many of the imaging techniques, is required for diagnostic accuracy [72].

\section{The role of bronchoscopy to diagnose and grade TBM}

We reviewed 27 papers on the role of bronchoscopy in the diagnostic work-up of TBM $[7,55,59,60]$. The Task Force members use flexible bronchoscopy in a spontaneous breathing child as a gold standard for the diagnosis of TM and BM. Rigid bronchoscopy plays a role but may splint the airway and is not as useful as flexible bronchoscopy in the evaluation of the airway dynamics. However, the limitations of flexible bronchoscopy must be appreciated. First, the bronchoscope occludes a significant part of the airway, likely raising airway pressure and reducing the chances of detecting malacia. Second, even for experienced bronchoscopists, assessment of changes in the lumen is subjective $[5,6,16,27,29,53,72-74]$. Third, there 
are also specific problems linked with the optical attributes of the instrument, i.e. the distortion of the image due to curvature and orientation of the lens [75]. Furthermore, the bronchoscopic diagnosis of TM and BM can be difficult in children because of the small size of the bronchial tree and the rapid respiratory rate. There are no studies comparing flexible and rigid bronchoscopy.

Good anaesthetic technique is essential in order not to mask (too deep) or exaggerate (too light with severe coughing) TM and BM, but the Task Force found a paucity of data in the literature on anaesthetic practice [76]. There are case reports of airway collapse with anaesthesia in patients with either symptomatic or asymptomatic TM [77-79]. Because general anaesthesia leads to increased collapsibility of
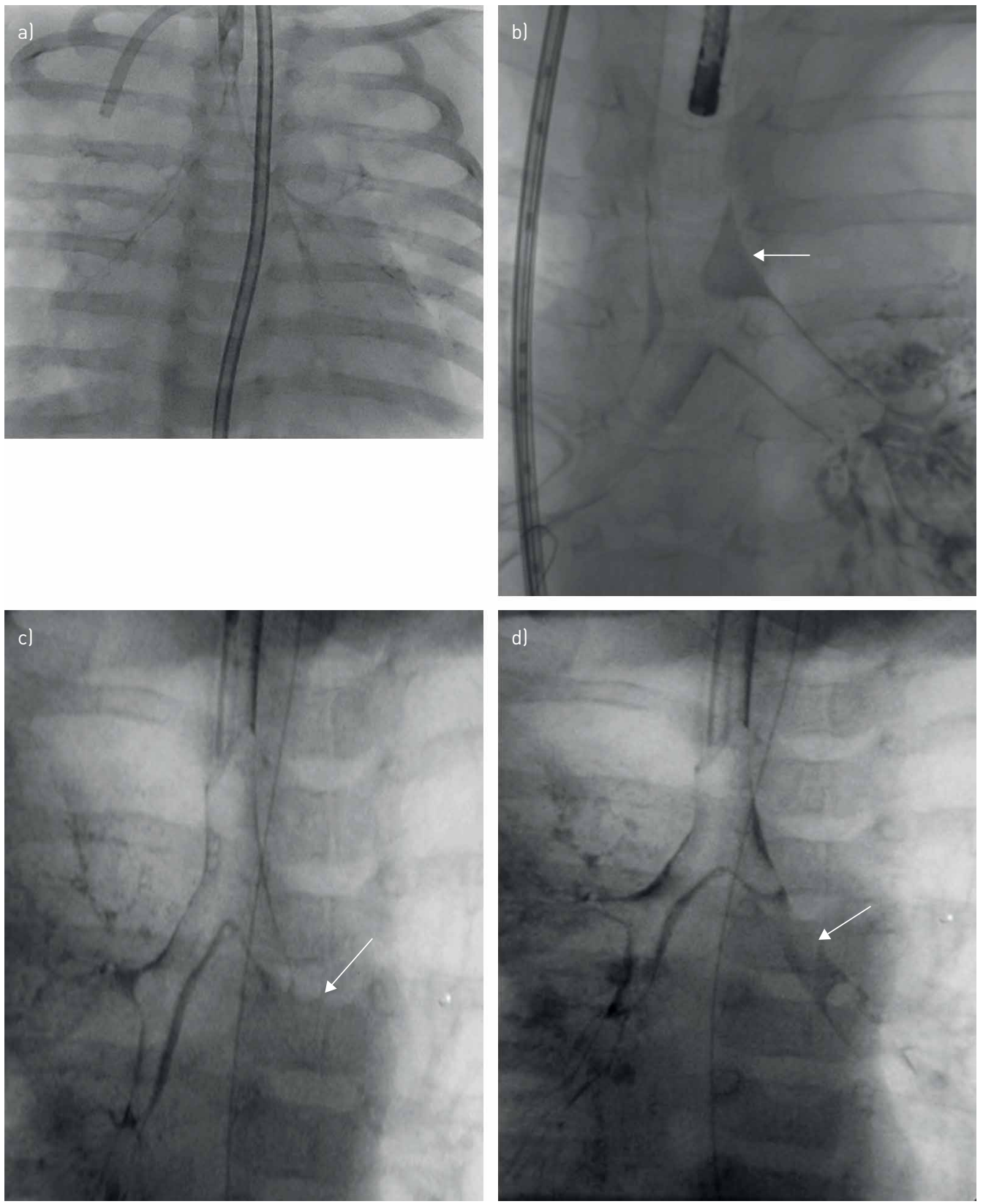

FIGURE 2 a) Bronchography image showing diffuse tracheobronchomalacia in a 7-month-old girl with 22q11 deletion, right aortic arch and an aberrant left subclavian artery. The tracheostomy tube has been withdrawn into the upper trachea. b) Bronchography image showing apposition of the anterior and posterior wall of the trachea (white arrow highlighting darker "smudge" effect) in a 1-year-old girl with tracheomalacia related to vascular compression. c) A 5-month-old girl with left pulmonary artery and vein hypoplasia with severe bronchomalacia of the left main bronchus. Bronchography image showing complete collapse of the left main bronchus (white arrow). d) Patient in (c) where continuous positive expiratory pressure (CPAP) is now applied. Bronchography image showing some opening of the left main bronchus with additional CPAP (white arrow). 
the upper airways the same might be true of the lower airways [53, 80-82]. The topic of the most suitable drugs for anaesthesia in bronchoscopy remains an area for future research.

In their bronchoscopy practice, the Task Force members divide the trachea into three arbitrary regions to describe the site and extent of TM: from the cricoid to the thoracic inlet, from the thoracic inlet to the mid portion of the intrathoracic trachea and from there to the carina. Examples of malacia are portrayed in figure 3.

Four papers attempt to refine the role of flexible bronchoscopy to quantify the degree of malacia. MASTERS et al. [75] and MASTERS [83] used digital video to capture and quantitate the images with high intra- and interobserver agreement. The authors demonstrated that neither the site nor the severity of malacia correlate with the clinical symptoms or severity. OKAZAKI et al. [84] quantitated the static pressure-area relationship of the trachea under general anaesthesia and paralysis. Finally, LoRING et al. [85] evaluated central airway narrowing in adults by a "shape index" based on images taken during bronchoscopy and plotted against the transtracheal pressure.

\section{Medical therapies in the management of TBM}

The following medical therapies for TBM are considered in the literature.

\section{$\beta_{2}$-agonists}

Malacia causing bronchodilator unresponsive wheeze is not uncommon [26]. There are theoretical reasons why bronchodilators, by lowering airway smooth muscle tone, may worsen airway obstruction. In one study, $V^{\prime} \operatorname{maxFRC}$ was below normal in infants with wheeze and malacia at baseline and did not improve after inhalation of $\beta_{2}$-agonists; infants with malacia were not more likely to worsen after $\beta_{2}$-agonists than nonmalacic, wheezy controls [86]. In older children with isolated TM, airways obstruction (reduced peak expiratory flow and forced expiratory volume in $1 \mathrm{~s}$, compatible with the increased central airway collapsibility during forced expiration) does not improve after bronchodilation [25]. Also, underlying bronchodilator responsiveness in a patient with severe TBM might only be detectable after optimal tracheal stabilisation [87].

\section{Ipratropium bromide}

In a retrospective study, 32 out of 52 children diagnosed with TM and treated with ipratropium bromide showed improvement in symptoms [88], although it is not possible to say whether the improvement may be related to its effect on airways secretions and/or airways tone.

\section{Muscarinic agonists}

Anecdotally, muscarinic agonists (e.g. bethanechol and methacholine) reduce tracheal compliance probably by causing trachealis constriction [51]. This is not routine clinical practice.
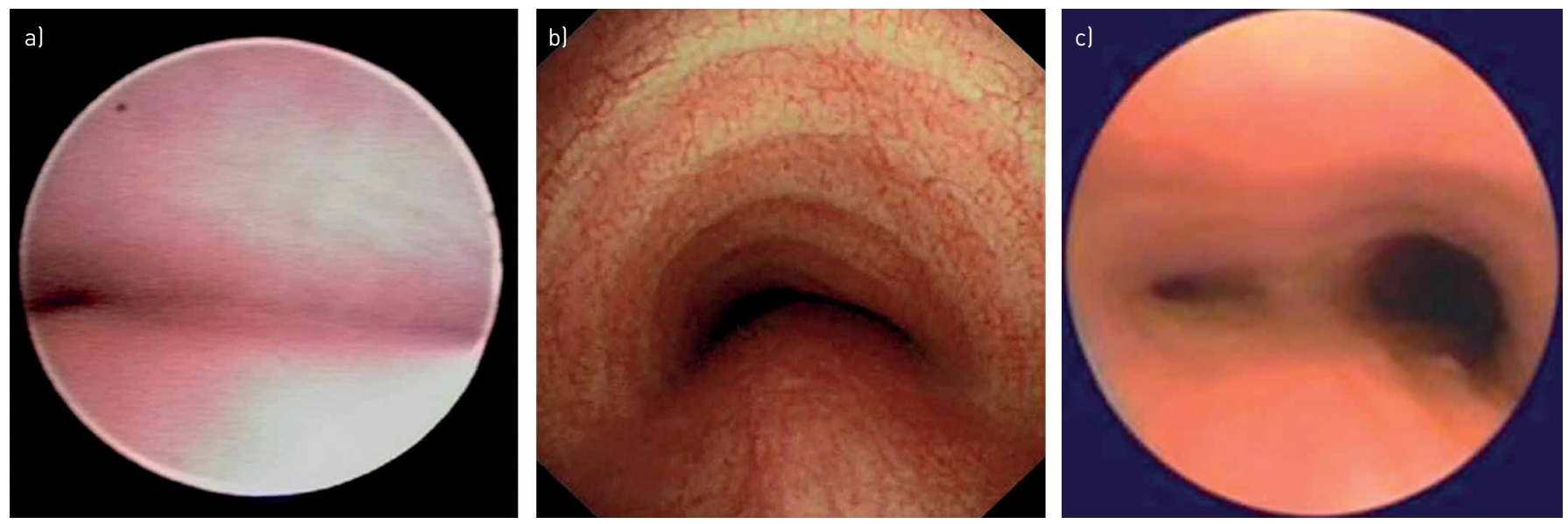

FIGURE 3 Bronchoscopic images. a) Severe malacia affecting the carina and opening of both right and left bronchi. b) Bronchoscopy image showing focal tracheomalacia and predominantly posterior membrane collapse in a 15-year-old boy with tracheo-oesophageal fistula and oesophageal atresia repaired at birth. c) Severe malacia affecting the left main bonchus. 


\section{Mucoactive agents}

A Cochrane review [89] found one eligible study and concluded likely harm from recombinant human DNase, although this was not evident from the original data after adjusting for baseline factors. The single study included in the review [90] showed that 2 weeks treatment with nebulised recombinant human DNase did not enhance recovery or reduce the need for antibiotics in children with airway malacia and a respiratory tract infection. Anecdotally, nebulised hypertonic saline may aid mucus clearance [27].

\section{Antibiotic therapies}

The relationship between airway malacia and protracted bacterial bronchitis is unclear [38, 39, 41, 91]. The juxtaposition of the anterior and posterior walls of the trachea results in recurrent vibrations and irritation of the airway, and reduced mucociliary clearance as the compressed airway impedes clearance of secretions, thus predisposing to distal infection [89]. Squamous metaplasia can develop over time, further impairing mucociliary clearance [6]. Between $14 \%$ and $52 \%$ of children with protracted bacterial bronchitis had TBM. Treatment for $\geqslant 2$ weeks with antibiotics resolved symptoms in the majority [41], although recurrence was common $[41,89]$.

The Task Force members apply a lower threshold for using antibiotics in children with known TBM and an acute exacerbation. Prophylactic azithromycin is often prescribed with only anecdotal evidence of benefit.

\section{Management of comorbidities/associations \\ Gastro-oesophageal reflux}

In one study, $70 \%$ of children aged 3-28 months with airway malacia had GOR $(n=28)$ compared with $39 \%(n=16)$ in controls [92]. This association does not imply causation.

\section{Eosinophilic oesophagitis}

These patients present with treatment nonresponsive GOR. Children with eosinophilic oesophagitis and airway symptoms appear to have worse outcomes than their counterparts with purely gastrointestinal symptoms [93]. Oesophageal eosinophilia is also seen after oesophageal atresia repair in $17 \%$ of children [94], many of whom have TM. This group has a significantly greater incidence of reflux symptoms, reactive airway disease, hypoxic spells (secondary to both TM and oesophageal dysfunction) and dysphagia when compared with the noneosinophilic group.

\section{General respiratory health}

All aspects of good respiratory healthcare should be emphasised, such as immunisations, flu vaccinations, dry warm housing, exercise and passive smoke avoidance.

\section{The role of respiratory physiotherapy}

Respiratory physiotherapy is commonly used in the treatment of children with TM or TBM, aiming to enhance mucociliary clearance [44,89]. Our review of the literature did not identify any studies investigating the effectiveness of physiotherapy for patients with TM. Moreover, we have not found any studies on the role of airway clearance techniques in conjunction with mucolytics. Positive expiratory pressure (PEP) is often used as an airway clearance technique in clinical practice. In infants with TM, continuous positive airway pressure (CPAP) increases maximal expiratory flow by raising FRC [47]. One study reports that a PEP of $5-10 \mathrm{~cm} \mathrm{H}_{2} \mathrm{O}$ increases the peak cough expiratory flow of children with clinically diagnosed TBM after TOF repair [95]. However, the authors of the study note that an increase of PEP above $15 \mathrm{cmH}_{2} \mathrm{O}$ may have a negative effect, suggesting there should be close monitoring of PEP or use of a threshold expiratory pressure device. It is unclear if PEP devices used for airway clearance prevent or reduce the impact of lower respiratory tract infections. Children with BM may experience exercise limitation [44], but we did not find any studies on exercise rehabilitation.

\section{Surgery including stenting for TBM}

Surgery may be necessary in severe TBM with acute life-threatening events ("apnoeic spells"), cyanosis, feeding difficulties, inability to extubate the airway and recurrent pneumonia [89]. A detailed diagnostic work-up informs planning for the most appropriate operative technique. Surgical and endoscopic options include tracheostomy, aortopexy, tracheal resection, tracheopexy (anterior or posterior), internal stenting and external airway splinting [27]. Intra-operative flexible bronchoscopy may be helpful in guiding the surgeon during some of these procedures [27, 96-98]. 


\section{Tracheostomy}

This technique was the mainstay of surgical treatment in the past, but is now used as a last resort $[27,99]$. The tracheosotomy tube provides internal airway stenting and enables long-term mechanical ventilation if necessary

\section{Aortopexy and tracheopexy}

The main indication for anterior aortopexy is short segment TM secondary to congenital TOF [27, 100, 101]. The ascending aorta or arch is pulled anteriorly to relieve pressure on the trachea. Aortopexy does not directly address airway malacia but creates more space around the mediastinal trachea so that the aorta, anteriorly, and the oesophagus, posteriorly, do not compress the airway [101]. Nevertheless, the evidence base for aortopexy is scant [102] with limited long-term follow-up data [103]. The approach may be a small left anterior thoracotomy, a partial upper sternotomy or thoracoscopy $[104,105]$. If bronchial collapse persists despite aortopexy, pulmonary artery suspension may be performed. Tracheal traction sutures can allow a more effective TM correction (anterior tracheopexy) [106-108]. A recent retrospective report showed that partial upper sternotomy and open thoracotomy had the highest rate of symptom resolution [98]. Reported overall effectiveness of aortopexy for TM, whatever surgical approach performed, is $>80 \%[101,102]$.

More recently there has been interest in posterior tracheopexy, because in many cases the major contributor to airway collapse is the posterior tracheal membrane protruding into the tracheal lumen during exhalation $[106,109]$. In this procedure the posterior tracheal membrane is sutured to the anterior longitudinal ligament of the spine through a posterior right thoracotomy. Preliminary results are encouraging [109]. Anterior and posterior tracheopexy may be combined, but this approach is not used widely [110].

\section{Tracheal resection}

Tracheal resection is sometimes considered in highly selected patients with short segment TM in whom other surgical or endoscopic techniques have failed. Severe suprastomal collapse in tracheotomised patients, also called peristomal TM, can also be an indication for a limited tracheal resection with end-to-end anastomosis $[99,111]$.

\section{Internal stenting for TBM}

Internal stenting is an attractive concept, but several practical problems limit the use of this technique in children [112]. The indications vary considerably, but in general a multidisciplinary team and an individualised approach to each patient are emphasised $[113,114]$. Most centres reserve the use of internal stents for children who have no curative surgical options and where tracheostomy is not appropriate [113-116]. Other centres consider stent implantation to be a valid alternative to tracheostomy [117]. Stent insertion is usually followed by an immediate improvement in the patient's clinical condition [118], although this may be transient.

Various stent types with different physical characteristics are available (table 3) [114]. Silicone stents [119] and self-expanding plastic stents [120] have rarely been used in children with TBM. Encrustation with

\begin{tabular}{|c|c|c|c|c|}
\hline Silicone (Dumon) & Semirigid & Easier to remove & $\begin{array}{c}\text { Prone to migration and/or } \\
\text { blockage }\end{array}$ & $\begin{array}{c}\text { Short duration use; palliative } \\
\text { care }\end{array}$ \\
\hline $\begin{array}{l}\text { Silicone (Polyflex) } \\
\text { self-expanding }\end{array}$ & Flexible & Relatively easier to remove & $\begin{array}{l}\text { Large delivery device; } \\
\text { difficult to insert; prone to } \\
\text { migration }\end{array}$ & Rarely used \\
\hline Metal self-expanding & Flexible & $\begin{array}{c}\text { Easy to insert; may be safer } \\
\text { if vascular compression is } \\
\text { present }\end{array}$ & $\begin{array}{l}\text { Very difficult to remove; } \\
\text { cannot be dilated with } \\
\text { growth }\end{array}$ & $\begin{array}{l}\text { In nearly fully grown child; } \\
\text { vascular compression }\end{array}$ \\
\hline $\begin{array}{l}\text { Bioabsorbable } \\
\text { self-expanding }\end{array}$ & $\begin{array}{l}\text { Will reabsorb over } \\
3-4 \text { months }\end{array}$ & $\begin{array}{l}\text { Can be custom-made for } \\
\text { individual child; offers a } \\
\text { temporary treatment option }\end{array}$ & $\begin{array}{l}\text { May require serial stenting; } \\
\text { expensive }\end{array}$ & $\begin{array}{c}\text { "Proof of principle" before more } \\
\text { definitive treatment; short-term } \\
\text { support following tracheal } \\
\text { surgery }\end{array}$ \\
\hline
\end{tabular}


FIGURE 4 A self-expanding stent inserted into the left main bronchus of the same child illustrated in figure $2 \mathrm{c}$ and $\mathrm{d}$ with immediate relief of symptoms.

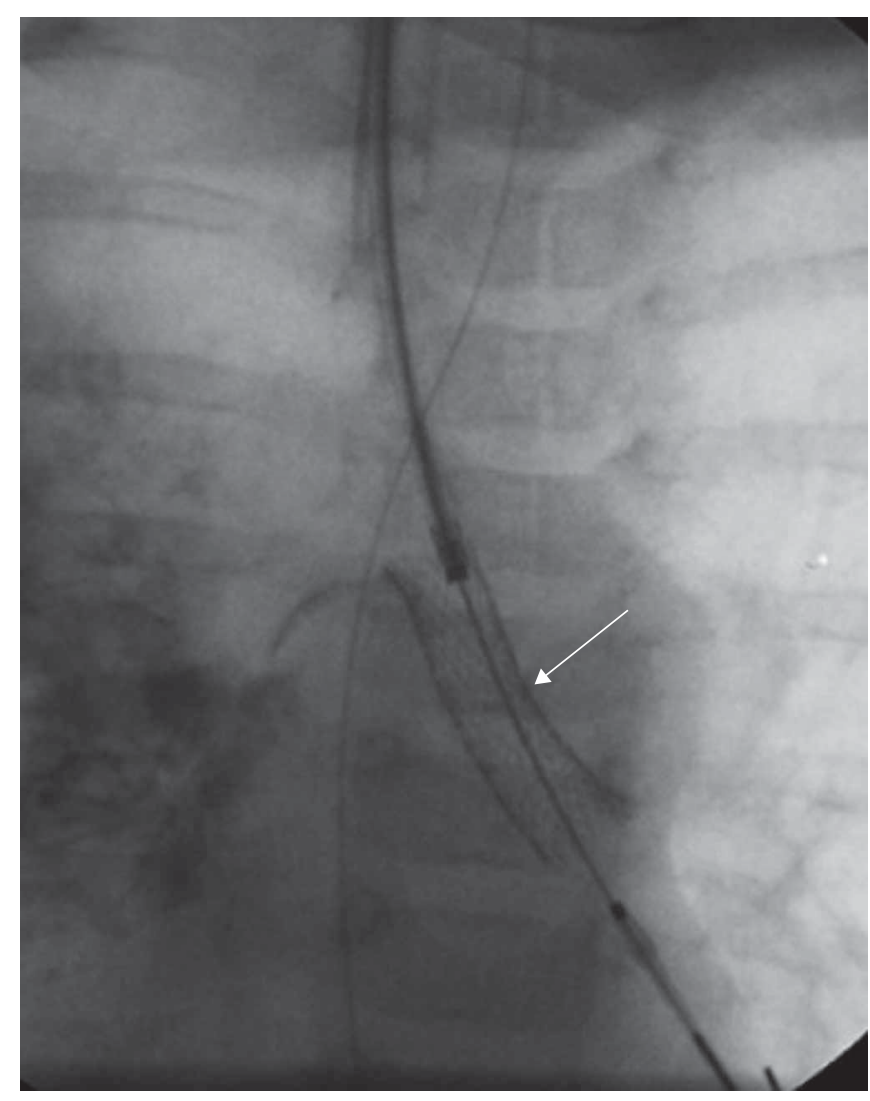

mucus, migration and the development of granulation tissue or mucosal hyperplasia at the ends of the stent are problems $[112,116,117,119,121]$. Balloon-expandable metals stents may be difficult to retrieve after being in situ for longer than a few weeks and may fracture or (rarely) cause vascular erosion [112-115, 117]. They may be dilated as the child grows (figure 4) $[112,114]$. Uncovered self-expanding metal stents are less likely to fracture or cause vascular erosion, but cannot be dilated and are very difficult to remove $[114,116]$. Covered self-expanding metal stents are retrievable, but suffer from the same problems as silicone stents $[112,114]$. Recently, bioabsorbable airway stents have been used in selected children with malacia (figure 5) $[117,122]$. Realistic goals for the use of absorbable stents include "proof of principle" that restoration of patency improves clinical status (e.g. by making the patient independent of
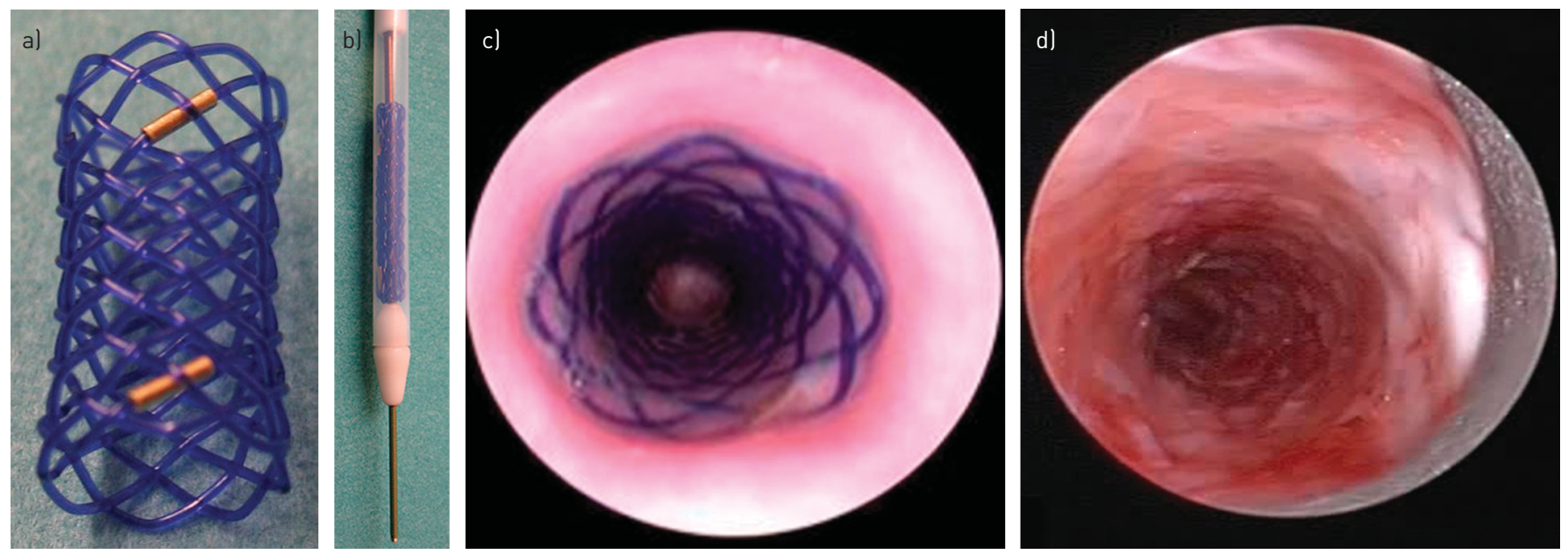

FIGURE 5 Biodegradable stents. a) A biodegradable stent. b) Stent within introducer. c) Bronchoscopic image of stent recently deployed. dl Bronchoscopic image of biodegradable stent after 8 weeks placement with evidence of partial reabsorption showing an open lumen and mild granulation tissue formation. 
invasive ventilation) before attempting surgery or permanent stenting $[112,113,115]$ and stabilisation of the airway to allow spontaneous resolution of malacia [115].

Extensive tracheobronchial stenting for diffuse TBM is not appropriate [112, 114], and it has been previously recommended to avoid a combination of stenting and tracheostomy [112, 113, 118]. Aortopexy is almost universally preferred over stenting for TM associated with oesophageal atresia [116, 123]. Metal stents [124], or serial stenting with absorbable stents [115], could be used as an alternative to aortopexy, but this concept has not been widely accepted.

Complications of metal stents include airway obstruction due to granulation tissue and mucus plugging, which is aggravated by the variable degree of impairment of mucociliary clearance caused by the stent $[112,116,125]$. Granulation tissue is usually managed by repeat bronchoscopic laser treatment, endoscopic removal or crushing with balloons $[112,126]$. Fatal complications, including severe airway haemorrhage and pneumonia, may occur, but are uncommon when stents are used appropriately [118, 127]. Fully epithelialised metal stents are usually considered permanent, as they are difficult to remove safely and the long-term results of permanent stenting are acceptable $[112,115,117,128]$.

\section{External splinting and tracheal reinforcement}

Extraluminal splinting may offer effective airway support in highly selected, very severe and/or diffuse TM/ TBM as an alternative to endoluminal stenting. Biocompatible ceramic rings, resorbable plates or even three-dimensional (3D) printed biodegradable splints have all been used [129-131]. Possible erosion into surrounding structures, a strangulation effect after somatic growth in a small child, infection and long-term tissue tolerance are concerns.

\section{Ventilatory pressure support in TBM}

There is a pathophysiological rationale for pressure support in paediatric TBM. The variable dynamic deformity throughout the airway results in variable airflow velocities and time constants of respiration. Pressure support must overcome these forces and concomitantly allow enough downstream expiratory gas flow to ensure respiratory stability. Computer modelling reveals a complex relationship between length of malacia, diameter of the tracheal ring, site of malacia and tissue type generally to predict the tipping point to airway collapse/closure or snap point [132-134]. These mathematical modelling studies provide some insight into the use of pressure support, but greater insight might come from 3D modelling of the airway lesions [135].

TBM has been managed with all forms of noninvasive pressure support (CPAP, bilevel airway pressure, high-flow drivers and full ventilation) [21, 136-140]. CPAP is the most widely used. Bilevel airway pressure is rarely used because there is no advantage in the vast majority of patients (other perhaps than in those who require a very high distending CPAP pressure) and poor synchronisation may be a problem [137]. Our literature search found no prospective or randomised studies that help inform decisions regarding when and how to use these approaches. Comorbidities also may affect decision making.

Clinical studies have shown that CPAP improved gas flows at FRC without changing the appearance of the flow-volume loop and, most importantly, flows were also still appreciably decreased compared with controls, particularly at lower lung volumes $[47,141]$. Bronchoscopy or imaging can help titrate CPAP levels [138].

Currently there are no proven management algorithms. Pressure support should be considered in acute severe life-threatening events, although maintaining a child on noninvasive ventilation $24 \mathrm{~h}$ a day without a tracheostomy is likely to prove impractical. Pressure support is usually considered in any patient with recurrent acute or chronic respiratory failure and sleep disordered breathing. Speculatively, it may also play a role in some patients with TBM associated with recurrent persistent bacterial bronchitis or recurrent pneumonia and poor growth where alternative surgical or medical therapies have failed [142].

Application of noninvasive pressure support is dependent on informed parental agreement for the intervention, type of device, interface interaction between device and patient, operator experience, and availability of sleep monitoring systems. These interventions may need to be established over a number of monitoring sessions with careful follow-up. Protocols are usually determined on an individual basis. Weaning protocols take into account the possible natural history of improvement $[2,21,47,139,140]$. Just how long these modes of pressure support are required for on a daily basis or cumulatively over a longer time period is also not known and likely to be individualised.

A tracheostomy for the delivery of positive pressure is reserved for more severe cases in whom other approaches have failed or where pressure support is required for most of the 24 h day [21, 43, 139, 140, 143]. 
BOX 1 Illustrative quotes from parents and carers

1 "I am glad that he has been diagnosed after seeing 3 doctors who all fobbed me off with "it's wind, give him infacol" ... but feel disappointed that there is nothing I can do for him!"\#

2 "I was so worried about all the noises she was making especially at night. I used to be up and down all night checking up on her as she sounded like she was choking."\#

3 "I have always visited friends even when they had kids with a cold etc but feel now I may be a bit more cautious." "ी

4 "I know what it's like to feel the glares and hear the negative comments from others who think I've brought a sick child to a public place when I know nothing about him is contagious."

5 "My son is now 6 years old the condition has not gone away as they said it would .... We were told he would grow out of the condition by the age of two."

\#: Mumsnet thread “floppy windpipe", 2005 (www.mumsnet.com/Talk/general_health/63818-floppywindpipe); ๆ: Mumsnet thread "My 4 month old diagnosed with laryngeal or trachea malacia - anyone got any experience?", 2009-2011 (www.mumsnet.com/Talk/childrens_health/714854-My-4-month-old-diagnosedwith-laryngeal-or-trachea-malacia); +: Megan Horwath, 2015 (https://themighty.com/2015/03/i-know-youtracheomalacia).

\section{Parent and patient perspective}

There are few published studies that specifically address this topic [144-146]. Grey literature searches identified discussion forums, blogs and news articles where parents, carers and patients shared experiences and sought advice. Key concerns for parents and carers are described in the following, with selected illustrative quotes from parents and carers in box 1.

\section{Getting a diagnosis}

Parents express frustration at the length of time to get a diagnosis and a lack of understanding from health professionals. While some parents feel relief to have a diagnosis, they have concerns about how to best support their child (quote 1 in box 1 ).

\section{Specific symptoms and knowing when it is "bad"}

Parents and carers have concerns about specific symptoms, including laboured and noisy breathing, feeding, weaning, and weight loss (quote 2 in box 1). They seek advice to identify when symptoms are "bad".

\section{Risk of interacting with other children and social impact}

Some families express concern about their child with TM/BM catching colds and they avoid exposure (quote 3 in box 1). Families may experience the stigma associated with having a "sick" or perceived contagious child (quote 4 in box 1).

\section{Information and support}

Parents and carers recognise the importance of being well informed. The need for timely, high-quality information, delivered in a variety of formats, is well recognised [144-146].

Families also seek support and reassurance from peers both face-to-face and online to gain practical information about their child's condition and likely outcomes [146].

Information should be timed carefully and sensitively, particularly in severe cases. Some parents find it difficult to handle too much information in the early stages or find stories of other children's treatment frightening [146].

\section{Long-term outcomes}

Parents and carers express concern about long-term TM/BM outcomes but reassure each other that improvement can occur in certain cases. Nevertheless, some parents note that their child has not fully recovered or improved as quickly as expected, making it difficult to reconcile their expectations (quote 5 in box 1). In some adolescents, mental health issues may arise. Parents also have concerns about the impact of long-term treatment. Understanding which symptoms require intervention and the long-term outcomes for their child are key concerns for families.

\section{Areas for future endeavour}

For any future research into this topic of malacia, it is important to have a working definition of TM, BM and TBM. All Task Force members perform flexible bronchoscopy under carefully regulated anaesthetic conditions with airways undistorted by endotracheal tubes or laryngeal masks, wherever possible, in order 
to get the best anatomical assessment of malacia during free breathing and forced expiratory manoeuvres such as coughing. In experienced hands, tracheobronchography provides invaluable information.

The Task Force members grade the degree of malacia as:

1. Normal: collapse up to $50 \%$ of the lumen.

2. Mild: loss of cross-sectional area (which may be asymmetrical) between $50 \%$ and $75 \%$.

3. Moderate: loss of cross-sectional area between $75 \%$ and $90 \%$.

4. Severe: $>90 \%$ loss of cross-sectional area.

The reliance of subjective visualisation may be replaced by enhanced digital quantification in the future.

The site and length of the affected area can also be assessed bronchoscopically. Contrast-enhanced tracheobronchography provides useful dynamic information as airway collapse is dependent on the properties of the airway and transmural airway pressure.

Using these defined criteria, standardised data collection in a prospective manner by a network of interested parties could establish much needed information on a number of key areas:

1. The natural history of this condition from premature infancy to mature adolescents.

2. The role and impact of current surgical interventions, such as the anterior and posterior pexy procedures, and the impact of these procedures on long-term growth and outcomes.

3. Studies into the use of antibiotic therapy in the prevention and treatment of infection in TBM.

4. Increasing awareness and establishing markers for the role of malacia in refractory respiratory illness, thereby reducing delay in the diagnosis and unnecessary therapies.

5. Registry data to establish the role of biodegradable stents in the management of TBM and the histological changes that may happen in the tracheal wall as part of the reabsorption process.

6. Clarity on the apparent disconnect between the extent and degree of malacia and the clinical presentation.

7. Long-term outcomes, including the management of realistic expectations around full recovery.

Acknowledgements: We thank Barbara Johnson (European Lung Foundation, Sheffield, UK) for stepping in to cover maternity leave for Courtney Coleman and providing invaluable input to the final draft. Our thanks go to Thomy Tonia, David Rigau and Valerie Vacccaro from the ERS methodology and support team (ERS, Lausanne, Switzerland) for their assistance and helpful advice throughout this project.

Author contributions: C. Wallis and K. Priftis coordinated the project and collated the contributions from all authors who otherwise contributed equally to the production of this Task Force report.

Support statement: Funding support was provided by the European Respiratory Society (TF-2016-21). Funding information for this article has been deposited with the Crossref Funder Registry.

Conflict of interest: C. Wallis has nothing to disclose. E. Alexopoulou has nothing to disclose. J.L. Antón-Pacheco has nothing to disclose. J.M. Bhatt reports personal fees from Vertex, outside the submitted work. A. Bush has nothing to disclose. A.B. Chang reports grants from National Health and Medical Research Council, Australia, and other funding from GSK, Up to Date and BMJ Evidence Centre, outside the submitted work. A-M. Charatsi has nothing to disclose. C. Coleman is an employee of European Lung Foundation. J. Depiazzi has nothing to disclose. K. Douros has nothing to disclose. E. Eber has nothing to disclose. M. Everard has nothing to disclose. A. Kantar has nothing to disclose. I.B. Masters has nothing to disclose. F. Midulla has nothing to disclose. R. Nenna has nothing to disclose. D. Roebuck has nothing to disclose. D. Snijders has nothing to disclose. K. Priftis has nothing to disclose.

\section{References}

Benjamin B. Tracheomalacia in infants and children. Ann Otol Rhinol Laryngol 1984; 93: 438-442.

Baxter JD, Dunbar JS. Tracheomalacia. Ann Otol Rhinol Laryngol 1963; 72: 1013-1023.

Masters IB, Chang AB, Patterson L, et al. Series of laryngomalacia, tracheomalacia, and bronchomalacia disorders and their associations with other conditions in children. Pediatr Pulmonol 2002; 34: 189-195.

4 Masters IB, Zimmerman PV, Chang AB. Longitudinal quantification of growth and changes in primary tracheobronchomalacia sites in children. Pediatr Pulmonol 2007; 42: 906-913.

5 Tan JZ, Ditchfield M, Freezer N. Tracheobronchomalacia in children: review of diagnosis and definition. Pediatr Radiol 2012; 42: 906-915.

6 Carden KA, Boiselle PM, Waltz DA, et al. Tracheomalacia and tracheobronchomalacia in children and adults: an in-depth review. Chest 2005; 127: 984-1005.

7 Lee EY, Mason KP, Zurakowski D, et al. MDCT assessment of tracheomalacia in symptomatic infants with mediastinal aortic vascular anomalies: preliminary technical experience. Pediatr Radiol 2008; 38: 82-88.

8 Lee EY, Zurakowski D, Waltz DA, et al. MDCT evaluation of the prevalence of tracheomalacia in children with mediastinal aortic vascular anomalies. J Thorac Imaging 2008; 23: 258-265.

9 Ngerncham M, Lee EY, Zurakowski D, et al. Tracheobronchomalacia in pediatric patients with esophagea atresia: comparison of diagnostic laryngoscopy/bronchoscopy and dynamic airway multidetector computed tomography. J Pediatr Surg 2015; 50: 402-407. 
Lee EY, Boiselle PM. Tracheobronchomalacia in infants and children: multidetector CT evaluation. Radiology 2009; 252: 7-22.

Goo HW. Free-breathing cine CT for the diagnosis of tracheomalacia in young children. Pediatr Radiol 2013; 43: 922-928.

Tan JZ, Crossett M, Ditchfield M. Dynamic volumetric computed tomographic assessment of the young paediatric airway: initial experience of rapid, non-invasive, four-dimensional technique. J Med Imaging Radiat Oncol 2013; 57: 141-148.

Greenberg SB, Dyamenahalli U. Dynamic pulmonary computed tomography angiography: a new standard for evaluation of combined airway and vascular abnormalities in infants. Int J Cardiovasc Imaging 2014; 30: 407-414.

Bergeron M, Cohen AP, Cotton RT. The management of cyanotic spells in children with oesophageal atresia Front Pediatr 2017; 5: 106.

27: e33-e35.

Kugler C, Stanzel F. Tracheomalacia. Thorac Surg Clin 2014; 24: 51-58.

Murgu S, Colt H. Tracheobronchomalacia and excessive dynamic airway collapse. Clin Chest Med 2013; 34 527-555.

Choo EM, Seaman JC, Musani AI. Tracheomalacia/tracheobronchomalacia and hyperdynamic airway collapse. Immunol Allergy Clin North Am 2013; 33: 23-34.

Murgu SD, Colt HG. Description of a multidimensional classification system for patients with expiratory central airway collapse. Respirology 2007; 12: 543-550.

Hysinger EB, Friedman NL, Padula MA, et al. Tracheobronchomalacia is associated with increased morbidity in bronchopulmonary dysplasia. Ann Am Thorac Soc 2017; 14: 1428-1435.

Hysinger EB, Panitch HB. Paediatric tracheomalacia. Paediatr Respir Rev 2016; 17: 9-15.

Dessoffy KE, Modaff P, Pauli RM. Airway malacia in children with achondroplasia. Am J Med Genet A 2014; 164A: 407-414.

Yalcin E, Dogru D, Ozcelik U, et al. Tracheomalacia and bronchomalacia in 34 children: clinical and radiologic profiles and associations with other diseases. Clin Pediatr 2005; 44: 777-781.

Adil E, Rager T, Carr M. Location of airway obstruction in term and preterm infants with laryngomalacia. Am J Otolaryngol 2012; 33: 437-440

Boogaard R, Huijsmans SH, Pijnenburg MW, et al Tracheomalacia and bronchomalacia in children: incidence and patient characteristics. Chest 2005; 128: 3391-3397.

Baraldi E, Donegà S, Carraro $\mathrm{S}$, et al. Tracheobronchomalacia in wheezing young children poorly responsive to asthma therapy. Allergy 2010; 65: 1064-1065.

Fraga JC, Jennings RW, Kim PC. Pediatric tracheomalacia. Semin Pediatr Surg 2016; 25: 156-164.

Javia L, Harris MA, Fuller S. Rings, slings, and other tracheal disorders in the neonate. Semin Fetal Neonatal Med 2016; 21: 277-284.

Snijders D, Barbato A. An update on diagnosis of tracheomalacia in children. Eur J Pediatr Surg 2015; 25 333-335.

Maeda K. Pediatric airway surgery. Pediatr Surg Int 2017; 33: 435-443. 2005; 26: 422-425.

Rohde M, Banner J, Byard RW. Congenital lesions associated with airway narrowing, respiratory distress, and unexpected infant and early childhood death. Forensic Sci Med Pathol 2005; 1: 91-96.

Peh G, Chow P, Haddad M, et al. Delayed presentation of tracheomalacia in an infant with long-gap esophageal atresia and distal tracheoesophageal fistula and a right aortic arch. J Pediatr Surg 2006; 41: 1788-1790.

Keng LT, Chang CJ. All that wheezes is not asthma: adult tracheomalacia resulting from innominate artery compression. Postgrad Med J 2017; 93: 54-55.

Chang AB, Gaffney JT, Eastburn MM, et al. Cough quality in children: a comparison of subjective vs. bronchoscopic findings. Respir Res 2005; 6: 3 .

Weinberger M, Abu-Hasan M. Pseudo-asthma: when cough, wheezing, and dyspnea are not asthma. Pediatrics 2007; 120: 855-864.

Hiebert JC, Zhao YD, Willis EB. Bronchoscopy findings in recurrent croup: a systematic review and meta-analysis. Int J Pediatr Otorhinolaryngol 2016; 90: 86-90.

Santiago-Burruchaga M, Zalacain-Jorge R, Vazquez-Cordero C. Are airways structural abnormalities more frequent in children with recurrent lower respiratory tract infections? Respir Med 2014; 108: 800-805.

Zgherea D, Pagala S, Mendiratta M, et al. Bronchoscopic findings in children with chronic wet cough. Pediatrics 2012; 129: e364-e369.

Masters IB, Zimmerman PV, Pandeya N, et al. Quantified tracheobronchomalacia disorders and their clinical profiles in children. Chest 2008; 133: 461-467.

Kompare M, Weinberger M. Protracted bacterial bronchitis in young children: association with airway malacia. J Pediatr 2012; 160: 88-92.

Doshi J, Krawiec ME. Clinical manifestations of airway malacia in young children. J Allergy Clin Immunol 2007; 120: $1276-1278$.

McNamara VM, Crabbe DC. Tracheomalacia. Paediatr Respir Rev 2004; 5: 147-154.

Finder JD. Primary bronchomalacia in infants and children. J Pediatr 1997; 130: 59-66.

Abdel-Rahman U, Simon A, Ahrens P, et al. Aortopexy in infants and children - long-term follow-up in twenty patients. World J Surg 2007; 31: 2255-2259.

Moore $\mathrm{P}$, Smith $\mathrm{H}$, Greer RM, et al. Pulmonary function and long-term follow-up of children with tracheobronchomalacia. Pediatr Pulmonol 2012; 47: 700-705.

Davis S, Jones M, Kisling J, et al. Effect of continuous positive airway pressure on forced expiratory flows in infants with tracheomalacia. Am J Respir Crit Care Med 1998; 158: 148-152.

Uchida DA. Late presentation of double aortic arch in school-age children presumed to have asthma: the benefits of spirometry and examination of the flow-volume curve. Respir Care 2009; 54: 1402-1404. 

following repair of oesophageal atresia and tracheo-oesophageal fistula. Eur Respir J 1994; 7: 1039-1047. van der Wiel EC, Hofhuis W, Holland WPJ, et al. Predictive value of infant lung function testing for airway malacia. Pediatr Pulmonol 2005; 40: 431-436.

51 Panitch HB, Keklikian EN, Motley RA, et al. Effect of altering smooth muscle tone on maximal expiratory flows in patients with tracheomalacia. Pediatr Pulmonol 1990; 9: 170-176.

52 Shepard JO, Flores EJ, Abbott GF. Imaging of the trachea. Ann Cardiothorac Surg 2018; 7: 197-209.

53 Austin J, Ali T. Tracheomalacia and bronchomalacia in children: pathophysiology, assessment, treatment and anaesthesia management. Paediatr Anaesth 2003; 13: 3-11.

54 Berrocal T, Madrid C, Novo S, et al. Congenital anomalies of the tracheobronchial tree, lung, and mediastinum embryology, radiology, and pathology. Radiographics 2004; 24: e17.

55 Sanchez MO, Greer MC, Masters IB, et al. A comparison of fluoroscopic airway screening with flexible bronchoscopy for diagnosing tracheomalacia. Pediatr Pulmonol 2012; 47: 63-67.

56 Berg E, Naseri I, Sobol SE. The role of airway fluoroscopy in the evaluation of children with stridor. Arch Otolaryngol Head Neck Surg 2008; 134: 415-418.

57 Douros K, Kremmydas G, Grammeniatis V, et al. Helical multi-detector CT scan as a tool for diagnosing tracheomalacia in children. Pediatr Pulmonol 2019; 54: 47-52.

58 Long FR, Castile RG. Technique and clinical applications of full-inflation and end-exhalation controlled-ventilation chest CT in infants and young children. Pediatr Radiol 2001; 31: 413-422.

59 Lee S, Im SA, Yoon JS. Tracheobronchomalacia in infants: the use of non-breath held 3D CT bronchoscopy. Pediatr Pulmonol 2014; 49: 1028-1035.

60 Su SC, Masters IB, Buntain H, et al. A comparison of virtual bronchoscopy versus flexible bronchoscopy in the diagnosis of tracheobronchomalacia in children. Pediatr Pulmonol 2017; 52: 480-486.

61 Deacon JWF, Widger J, Soma MA. Paediatric tracheomalacia - a review of clinical features and comparison of diagnostic imaging techniques. Int J Pediatr Otorhinolaryngol 2017; 98: 75-81.

62 Lee EY, Strauss KJ, Tracy DA, et al. Comparison of standard-dose and reduced-dose expiratory MDCT techniques for assessment of tracheomalacia in children. Acad Radiol 2010; 17: 504-510.

63 Faust RA, Remley KB, Rimell FL. Real-time, cine magnetic resonance imaging for evaluation of the pediatric airway. Laryngoscope 2001; 111: 2187-2190.

64 Faust RA, Rimell FL, Remley KB. Cine magnetic resonance imaging for evaluation of focal tracheomalacia: innominate artery compression syndrome. Int J Pediatr Otorhinolaryngol 2002; 65: 27-33.

65 Ciet P, Wielopolski P, Manniesing R, et al. Spirometer-controlled cine magnetic resonance imaging used to diagnose tracheobronchomalacia in paediatric patients. Eur Respir J 2014; 43: 115-124.

66 Rimell FL, Shapiro AM, Meza MP, et al. Magnetic resonance imaging of the pediatric airway. Arch Otolaryngol Head Neck Surg 1997; 123: 999-1003.

67 Manimtim WM, Rivard DC, Sherman AK, et al. Tracheobronchomalacia diagnosed by tracheobronchography in ventilator-dependent infants. Pediatr Radiol 2016; 46: 1813-1821.

68 McLaren CA, Elliott MJ, Roebuck DJ. Tracheobronchial intervention in children. Eur J Radiol 2005; 53: 22-34.

69 Mok Q. Airway problems in neonates - a review of the current investigation and management strategies. Front Pediatr 2017; 5: 60.

70 Tan KL, Chong AW, Amin MA, et al. Iatrogenic tracheal flap mimicking tracheal stenosis with resultant stridor J Laryngol Otol 2012; 126: 751-755.

71 Chen Q, Langton-Hewer S, Marriage S, et al. Influence of tracheobronchomalacia on outcome of surgery in children with congenital heart disease and its management. Ann Thorac Surg 2009; 88: 1970-1974.

72 Masters IB, Chang AB. Tracheobronchomalacia in children. Expert Rev Respir Med 2009; 3: 425-439.

73 Wright CD. Tracheomalacia. Chest Surg Clin N Am 2003; 13: 349-357.

74 Nemes RM, Postolache P, Cojocaru DC, et al. Tracheomalacia in children and adults - not so rare as expected. Rev Med Chir Soc Med Nat Iasi 2014; 118: 608-611.

75 Masters IB, Eastburn MM, Francis PW, et al. Quantification of the magnification and distortion effects of a pediatric flexible video-bronchoscope. Respir Res 2005; 6: 16.

76 Majid A, Gaurav K, Sanchez JM, et al. Evaluation of tracheobronchomalacia by dynamic flexible bronchoscopy. A pilot study. Ann Am Thorac Soc 2014; 11: 951-955.

77 Asai T, Shingu K. Airway obstruction in a child with asymptomatic tracheobronchomalacia. Can J Anaesth 2001; 48: 684-687.

78 Okuda Y, Sato H, Kitajima T, et al. Airway obstruction during general anaesthesia in a child with congenital tracheomalacia. Eur J Anaesthesiol 2000; 17: 642-644.

79 Oh AY, Kim YH, Kim BK, et al. Unexpected tracheomalacia in Marfan syndrome during general anesthesia for correction of scoliosis. Anesth Analg 2002; 95: 331-332.

80 Eastwood PR, Szollosi I, Platt PR, et al. Collapsibility of the upper airway during anesthesia with isoflurane. Anesthesiology 2002; 97: 786-793.

81 Hillman DR, Walsh JH, Maddison KJ, et al. Evolution of changes in upper airway collapsibility during slow induction of anesthesia with propofol. Anesthesiology 2009; 111: 63-71.

82 Eastwood PR, Platt PR, Shepherd K, et al. Collapsibility of the upper airway at different concentrations of propofol anesthesia. Anesthesiology 2005; 103: 470-477.

83 Masters IB. A new method for objective identification and measurement of airway lumen in paediatric flexible videobronchoscopy. Thorax 2005; 60: 652-658.

84 Okazaki J, Isono S, Hasegawa $\mathrm{H}$, et al. Quantitative assessment of tracheal collapsibility in infants with tracheomalacia. Am J Respir Crit Care Med 2004; 170: 780-785.

85 Loring SH, O'Donnell CR, Feller-Kopman DJ, et al. Central airway mechanics and flow limitation in acquired tracheobronchomalacia. Chest 2007; 131: 1118-1124.

86 Hofhuis W, van der Wiel EC, Tiddens $\mathrm{H}$, et al. Bronchodilation in infants with malacia or recurrent wheeze. Arch Dis Child 2003; 88: 246-249.

87 Wagner BP, Birrer P, Tönz M, et al. Bronchodilator responsiveness in a ventilator-dependent infant with severe tracheobronchomalacia. Intensive Care Med 1999; 25: 729-732. 
Gallagher T, Maturo S, Fracchia S, et al. An analysis of children with tracheomalacia treated with ipratropium bromide (Atrovent). The Laryngoscope 2011; 121: S211-S211.

Goyal V, Masters IB, Chang AB. Interventions for primary (intrinsic) tracheomalacia in children. Cochrane Database Syst Rev 2012; 10: CD005304.

Boogaard R, de Jongste JC, Vaessen-Verberne AAPH, et al. Recombinant human DNase in children with airway malacia and lower respiratory tract infection. Pediatr Pulmonol 2009; 44: 962-969.

De Baets F, De Schutter I, Aarts C, et al. Malacia, inflammation and bronchoalveolar lavage culture in children with persistent respiratory symptoms. Eur Respir J 2012; 39: 392-395.

Bibi H, Khvolis E, Shoseyov D, et al. The prevalence of gastroesophageal reflux in children with tracheomalacia and laryngomalacia. Chest 2001; 119: 409-413.

Hill CA, Ramakrishna J, Fracchia MS, et al. Prevalence of eosinophilic esophagitis in children with refractory aerodigestive symptoms. JAMA Otolaryngol Head Neck Surg 2013; 139: 903.

Dhaliwal J, Tobias V, Sugo E, et al. Eosinophilic esophagitis in children with esophageal atresia: eosinophilic esophagitis in esophageal atresia. Dis Esophagus 2014; 27: 340-347.

Sirithangkul S, Ranganathan S, Robinson PJ, et al. Positive expiratory pressure to enhance cough effectiveness in tracheomalacia. J Med Assoc Thai 2010; 93: Suppl. 6, S112-S118.

Briganti V, Oriolo L, Mangia G, et al. Tracheomalacia in esophageal atresia. Usefulness of preoperative imaging evaluation for tailored surgical correction. J Pediatr Surg 2006; 41: 1624-1628.

Filler RM, de Fraga JC. Tracheomalacia. Semin Thorac Cardiovasc Surg 1994; 6: 211-215.

Jennings RW, Hamilton TE, Smithers CJ, et al. Surgical approaches to aortopexy for severe tracheomalacia. J Pediatr Surg 2014; 49: 66-70.

Anton-Pacheco JL, Garcia-Hernandez G, Villafruela MA. The management of tracheobronchial obstruction in children. Minerva Pediatr 2009; 61: 39-52.

Corbally MT, Spitz L, Kiely E, et al. Aortopexy for tracheomalacia in oesophageal anomalies. Eur J Pediatr Surg 1993; 3: 264-266.

Filler RM, Messineo A, Vinograd I. Severe tracheomalacia associated with esophageal atresia: results of surgical treatment. J Pediatr Surg 1992; 27: 1136-1140. the literature. Ital J Pediatr 2012; 38: 62.

Montgomery J, Sau C, Clement W, et al. Treatment of tracheomalacia with aortopexy in children in Glasgow. Eur J Pediatr Surg 2014; 24: 389-393.

Arnaud AP, Rex D, Elliott MJ, et al. Early experience of thoracoscopic aortopexy for severe tracheomalacia in infants after esophageal atresia and tracheo-esophageal fistula repair. J Laparoendosc Adv Surg Tech A 2014; 24: 508-512.

van der Zee DC, Straver M. Thoracoscopic aortopexy for tracheomalacia. World J Surg 2015; 39: 158-164.

Fraga JC, Calkoen EE, Gabra HO, et al. Aortopexy for persistent tracheal obstruction after double aortic arch repair. J Pediatr Surg 2009; 44: 1454-1457.

Morabito A, MacKinnon E, Alizai N, et al. The anterior mediastinal approach for management of tracheomalacia. J Pediatr Surg 2000; 35: 1456-1458.

Yokoi A, Arai H, Bitoh Y, et al. Aortopexy with tracheal reconstruction for postoperative tracheomalacia in congenital tracheal stenosis. J Pediatr Surg 2012; 47: 1080-1083.

52: 951-955.

Shieh HF, Smithers CJ, Hamilton TE, et al. Descending aortopexy and posterior tracheopexy for severe tracheomalacia and left mainstem bronchomalacia. Semin Thorac Cardiovasc Surg 2019; 31: 479-485.

Monnier P. Tracheotomy. In: Monnier P, ed. Pediatric Airway Surgery. Berlin, Springer, 2011; pp. 325-336.

Wallis C, McLaren CA. Tracheobronchial stenting for airway malacia. Paediatr Respir Rev 2018; 27: 48-59.

de Trey LA, Dudley J, Ismail-Koch $\mathrm{H}$, et al. Treatment of severe tracheobronchomalacia: ten-year experience. Int J Pediatr Otorhinolaryngol 2016; 83: 57-62.

Nicolai T. Airway stents in children. Pediatr Pulmonol 2008; 43: 330-344.

Antón-Pacheco JL, Luna C, García E, et al. Initial experience with a new biodegradable airway stent in children is this the stent we were waiting for? Pediatr Pulmonol 2016; 51: 607-612.

Anton-Pacheco JL, Cabezali D, Tejedor R, et al. The role of airway stenting in pediatric tracheobronchia obstruction. Eur J Cardiothorac Surg 2008; 33: 1069-1075.

Serio P, Fainardi V, Leone R, et al. Tracheobronchial obstruction: follow-up study of 100 children treated with airway stenting. Eur J Cardiothorac Surg 2014; 45: e100-e109. Otol Rhinol Laryngol 2004; 113: 641-647. Pulmonol 2005; 39: 21-27.

Tibballs J, Fasulakis S, Robertson CF, et al. Polyflex stenting of tracheomalacia after surgery for congenital tracheal stenosis. Int J Pediatr Otorhinolaryngol 2007; 71: 159-163.

Serio P, Nenna R, Di Maurizio M, et al. Outcome of long-term complications after permanent metallic left bronchial stenting in children. Eur I Cardiothorac Surg 2018; 53: 610-617.

Vondrys D, Elliott MJ, McLaren CA, et al. First experience with biodegradable airway stents in children. Ann Thorac Surg 2011; 92: 1870-1874.

3 Valerie EP, Durrant AC, Forte V, et al. A decade of using intraluminal tracheal/bronchial stents in the management of tracheomalacia and/or bronchomalacia: is it better than aortopexy? J Pediatr Surg 2005; 40: 904-907.

Yang CF, Soong WJ, Jeng MJ, et al. Esophageal atresia with tracheoesophageal fistula: ten years of experience in an institute. J Chin Med Assoc 2006; 69: 317-321.

Furman RH, Backer CL, Dunham ME, et al. The use of balloon-expandable metallic stents in the treatment of pediatric tracheomalacia and bronchomalacia. Arch Otolaryngol Head Neck Surg 1999; 125: 203-207.

Soong WJ, Tsao PC, Lee YS, et al. Flexible endoscopy for pediatric tracheobronchial metallic stent placement, maintenance and long-term outcomes. PLoS One 2018; 13: e0192557. 
Stotz WH, Berkowitz ID, Hoehner JC, et al. Fatal complication from a balloon-expandable tracheal stent in a child: a case report. Pediatr Crit Care Med 2003; 4: 115-117.

128 Nicolai T, Huber RM, Reiter K, et al. Metal airway stent implantation in children: follow-up of seven children. Pediatr Pulmonol 2001; 31: 289-296.

129 Amedee RG, Mann WJ, Lyons GD. Tracheomalacia repair using ceramic rings. Otolaryngol Head Neck Surg 1992; 106: 270-274.

130 Gorostidi F, Reinhard A, Monnier P, et al. External bioresorbable airway rigidification to treat refractory localized tracheomalacia. Laryngoscope 2016; 126: 2605-2610.

131 Morrison RJ, Sengupta S, Flanangan CL, et al. Treatment of severe acquired tracheomalacia with a patient-specific, 3D-printed, permanent tracheal splint. JAMA Otolaryngol Head Neck Surg 2017; 143: 523-525.

132 Heil M. Stokes flow in collapsible tubes: computation and experiment. J Fluid Mech 1997; 353: 285-312.

133 Hollister SJ, Hollister MP, Hollister SK. Computational modeling of airway instability and collapse in tracheomalacia. Respir Res 2017; 18: 62.

134 Kamm RD, Pedley TJ. Flow in collapsible tubes: a brief review. J Biomech Eng 1989; 111: 177-179.

135 Xu C, Brennick MJ, Dougherty L, et al. Modeling upper airway collapse by a finite element model with regional tissue properties. Med Eng Phys 2009; 31: 1343-1348.

136 Vezina K, Laberge S, Nguyen TTD. Home high-flow nasal cannula as a treatment for severe tracheomalacia: a pediatric case report. Pediatr Pulmonol 2017; 52: E43-E45.

137 Essouri S, Nicot F, Clement A, et al. Noninvasive positive pressure ventilation in infants with upper airway obstruction: comparison of continuous and bilevel positive pressure. Intensive Care Med 2005; 31: 574-580.

138 Miller RW, Pollack MM, Murphy TM, et al. Effectiveness of continuous positive airway pressure in the treatment of bronchomalacia in infants: a bronchoscopic documentation. Crit Care Med 1986; 14: 125-127.

139 Fayon M, Donato L. Tracheomalacia (TM) or bronchomalacia (BM) in children: conservative or invasive therapy. Arch Pediatr 2010; 17: 97-104.

140 Murgu SD, Colt HG. Tracheobronchomalacia and excessive dynamic airway collapse. Respirology 2006; 11: 388-406.

141 Panitch HB, Allen JL, Alpert BE, et al. Effects of CPAP on lung mechanics in infants with acquired tracheobronchomalacia. Am J Respir Crit Care Med 1994; 150: 1341-1346.

142 Armstrong D. The use of continuous positive airway pressure or non-invasive ventilation as forms of respiratory support in children with cystic fibrosis. Paediatr Respir Rev 2013; 14: Suppl. 1, 19-21.

143 Jacobs IN, Wetmore RF, Tom LW, et al. Tracheobronchomalacia in children. Arch Otolaryngol Head Neck Surg 1994; 120: 154-158.

144 Coffey JS. Parenting a child with chronic illness: a metasynthesis. Pediatr Nurs 2006; 32: 51-59.

145 Kepreotes E, Keatinge D, Stone T. The experience of parenting children with chronic health conditions: a new reality. J Nurs Healthc Chronic Illn 2010; 2: 51-62. McFeeters M. The lived experiences of hospital for parents of children commenced on invasive long-term
ventilation [PhD Thesis]. 2016. www.dora.dmu.ac.uk/xmlui/handle/2086/13059 Date last accessed: July 17, 2019. 